\title{
Profile of Person Affected by Leprosy with Clinical Relapse among in High Endemic State of India
}

\author{
Sunil Vilasrao Gitte ${ }^{1}$, Chaitanya Nigam ${ }^{1}$, Ashish B Chakraborty ${ }^{1}$, Krishnamurty Kamble ${ }^{1}$, Mukesh Soni ${ }^{1}$, \\ Rupam Gahlot ${ }^{2}$ \\ ${ }^{1}$ Regional Leprosy Training and Research Institute, Lalpur, Raipur, Chhattisgarh, India \\ ${ }^{2}$ Department of Microbiology, Government Medical College, Rajnandgaon, Chhattisgarh, India
}

\begin{abstract}
Objective: Relapse is not an unusual phenomenon in leprosy, there are many predisposing factors which may lead to occurrence of relapse; some of these include the presence of persistent bacilli, drug monotherapy, inadequate or irregular therapy. Patients usually presents with presence of multiple skin lesions and/or thickened nerves, reason for early relapse is probably bacillary persistence due to inadequate treatment and for late relapse due to or re-infection. The objectives of this study are to assess various clinico-epidemiological factors associated with the occurrence of relapses in leprosy patients.
\end{abstract}

Methods: A hospital record based retrospective follow-up study has been performed and 117 relapse cases of leprosy were included. Leprosy relapse cases presented in the study hospital were interviewed using a predesigned and pretested preformed. Each patient was subjected to clinical, bacteriological and disability assessments for diagnosis of relapse and followed until the completion of multi drug therapy.

Results: During a study period, relapse was seen more in male as compared to female. The duration between cessation of treatment and re-appearance of new lesions varied from 1 to 33 years. Disability proportion was high among MB patients.

Conclusion: Relapse in leprosy should be thoroughly examined and looked for drug resistance. J Microbiol Infect Dis 2018; 8(3):103-107

Keywords: Drug resistance, Disability, Leprosy, MDT, Multibacillary, Paucibacillary, Relapse

\section{INTRODUCTION}

Relapse in leprosy indicates failure of treatment either complete or partial and it is affected by many factors $[1,2]$. Relapse rate in the country is an important indicator to assess of efficacy of therapeutic regimens incorporated to reduce the disease transmission in the community. The world has seen a drastic improvement in all parameters after the introduction of multi-drug therapy (MDT) for the control of leprosy. In Year 2012 alone a total of 3427 leprosy relapse cases were reported from 105 countries and many more relapse cases are being reported since then. Many countries have started reporting of relapse cases, which is a matter of concern in the current scenario so continuous monitoring of relapse cases with relation to treatment completion and drug resistance would be useful to plan next strategy to contain the disease [3].

India has achieved the goal of elimination at national level in the year 2005 and now focusing on sub national level elimination. The national leprosy elimination program in India is now giving more emphasis to disability prevention and Medical rehabilitation along with insurance of provision of quality services to patient affected by leprosy. The year, 2012-2013 National data of India revealed that a total of 221 relapse cases were confirmed and treated at District Hospitals [4].

On an average approximately 450 cases are suspected and out of them near about 321

Correspondence: Dr. Rupam Gahlot, Department of Microbiology, Government Medical Collage, Rajnandgaon, Chhattisgarh, India

Email: rupam.gahlot@gmail.com

Received: 03 March 2018 Accepted: 19 July 2018

Copyright (C JMID / Journal of Microbiology and Infectious Diseases 2018, All rights reserved 
average cases confirmed and treated for relapse every year in India. Chhattisgarh is one of the endemic states remaining for leprosy elimination in India, in March 2016; annual new case detection rate (ANCDR) of Chhattisgarh alone was about four times of the country. [4-9].

A total 120 suspected relapse were presented in our institute from year 2010 to 2017 and of which 117 were diagnosed as relapse.

\section{METHODS}

We designed a retrospective follow-up study to assess clinic-epidemiological and bacterial determination and to identify the factors associated with the occurrence of relapses in leprosy patients presented at our Institute from April 2010 to March 2017. The demographic details, clinical feature, the previous type of the disease, the nature of the lesions, type of treatment given and its duration, time interval between the release from treatment (RFT) and relapse (the incubation period of relapse) and the type of disease after relapse was recorded. All study subjects were examined clinically and bacteriologically. Each confirmed relapse case was categorized and treated as per the WHO guidelines [10] [for MB patient with high Bacteriological Index (BI) Multi Drug Therapy for more than 12 months and National Leprosy Eradication Programme India guidelines which is "MDT is restarted. Relapse must be differentiated from Leprosy reactions."] Patients were followed up until the completion of treatment for drug intake and clinical conditions and disability grading was also done during the course and necessary medical or surgical relief was provided.

\section{Definitions}

\section{Relapse}

We followed two criteria for diagnosis of relapse in leprosy as follows:

\section{a-Clinical criteria}

A patient who has successfully completed an adequate course of MDT, but subsequently develops new sign and symptoms of the disease after taking a complete treatment was taken as relapse.

Gradual or insidious appearance of a new lesion(s) or definite increase in the size of the lesion and/or appearances of new nerve thickening are seen in such cases of relapse. [Most of our cases fall under these criteria.]

\section{b-Microbiological criteria}

However, an increase in $\mathrm{BI}$ of even 2+ log at any site over the previous $\mathrm{BI}$ in two successive examinations were also considered as adequate supporting evidence for diagnosing relapse in patients who had earlier become negative or were showing a downward trend in BI after MDT treatment. Only those cases that were diagnosed and treated from our institute previously fulfil these criteria.

\section{Lepra reaction}

Any sudden redness, swelling of the lesion with or without a new lesion, especially during the first 6-12 months of follow-up was considered as lepra reaction.

All patients were designated and confirmed as relapse after excluding lepra reactions.

\section{RESULTS}

In total 117 relapse cases were registered and followed until the release from treatment (RFT). Most of the leprosy relapse patients belonged to age group 20-45 years and no statically significant association found between present classification and age $(p=0.299)$ (Table 1). Male gender was predominant with $90(77 \%)$ male and $27(23 \%)$ female patients (Table 2).

Table-1: Age wise classification of relapse cases

\begin{tabular}{lcccc}
\hline Variables & & PB & MB & Total \\
\hline \multirow{3}{*}{ Age in years } & $<20$ & 1 & 4 & 5 \\
& $20-40$ & 5 & 58 & 63 \\
& $40-60$ & 1 & 34 & 35 \\
Total & $>60$ & 0 & 14 & 14 \\
\hline
\end{tabular}

In total, $110 \mathrm{MB}(94 \%)$ cases were registered in comparison to only seven (6\%) PB cases. We have found more $\mathrm{MB}(\mathrm{N}=110)$ cases as compare to $\mathrm{PB}(\mathrm{N}=7)$ whereas on looking to their previous classification the MB/PB ratio was 80/37 [Table4]. When we further analyzed the data we found that all MB cases were presented as MB whereas 30 PB cases in their previous classification were presents as $M B$ when diagnosed as relapse. Rural: urban proportion was found as $66: 51$. Thirty-one (26.4\%) cases had relapse within five years of RFT, 40 were 
between five to 10 years and 44 were presented more than 10 years of RFT (Table 3). Sevenfour $(63.2 \%)$ cases were having no disability at the time of presentation, eight $(6.8 \%)$ were presented with Grade- 1 disability and 35 (29.9\%) were presented with Grade-2 disability.

Table 2. Gender wise distribution of Relapse cases.

\begin{tabular}{ccccc}
\hline Variables & & Female & Male & Total \\
& & & & \\
Type of leprosy & PB & 1 & 6 & 7 \\
& MB & 26 & 84 & 110 \\
Total & & 27 & 90 & \\
\hline
\end{tabular}

Table 3. Duration of relapse and type of Leprosy.

\begin{tabular}{lcccc}
\hline Variables & & PB & MB & Total \\
\hline & $<5$ & 5 & 27 & 32 \\
Duration in years & $5-10$ & 1 & 40 & 41 \\
& $>10$ & 1 & 43 & 44 \\
Total & & 7 & 110 & 117 \\
\hline
\end{tabular}

\section{DISCUSSION}

In our study the highest numbers of relapse cases belonged to age group 20-60 which may be due high number of leprosy cases belong to this age group, high exposure (as these age group people are the earning members of the family so more exposed to community for bread and butter rather than children and old age/ retired person) and long incubation period (about 5 years to 30 years [11-13]) of the disease may also contribute to the situation [14]. BCG vaccine has shown some protective effect among children less than four years [15-18] so this population is not generally affected and if a person is affected in childhood $(<18$ years of age) and take complete treatment, he or she is likely to relapse after a few years hence this may be a probable reason that $20-60$ age group is most affected age group.

There was male preponderance as compared to female (in our study approximate ratio was 3:1) which corresponds to level of exposure to the disease among male as compared to female in the community and possibly because of the higher prevalence of leprosy in males too $[14,19]$. Very few published studies are available in the literature in which this much large number of relapse patients are discussed so it is difficult to compare our study results with them $[14,20,21]$.

Case ratio from rural to urban was 1.29 which indicates slightly higher incidence in rural population. This may be due to low level of education, non-availability of MDT at the drug distribution points in the periphery and nonadherence to treatment properly [22] and there may be some contribution of diet [23].

MB cases are usually diagnosed as MB on relapse even after years of RFT as per the present guidelines which depend mainly on counting the number of patches to declare as MB or PB. As leprosy patches remains for life even after released from treatment (RFT). RFT is the term used in national programs where cure of the patient could not be measured by negative results by laboratory or clinical relief ( as both are usually absent in leprosy cases, many a times slit skin smear result is positive for long period even after stoppage of treatment and patches of leprosy never turns to normal for whole life) thus patients is given fixed dose treatment for a specific period and then declared as RFT] [24] when in case of relapse patient presents to OPD old patches are also counted along with new patches hence we found more MB cases.

These may be misleading as categorization of PB and MB is only for therapeutic purpose and this classification was developed according to bacillary burden in the body. We have to follow a different guideline for categorization of leprosy and definition of the relapse. Relapse rate per 1000 person years as per the latest reports [25] is 0.15 for MB cases and 0.55 for PB cases. The time interval between Released from Treatment and relapse ranged from one year to 33 years, and the median was 10 years (SD 8.0). In previously classified PB cases, early relapse (within 5 years of MDT) was observed in 12 $(32.4 \%)$ and late relapse (after 5 years of MDT) in 25 cases $(67.5 \%)$. In MB cases, early relapse (within five years) was observed in 10 (12.5\%) and late relapse (after five years of MDT) were $70(87.5 \%)$. It is important to note time duration 
of relapse after RFT as this gives us some idea about cause of relapse. Early relapse of leprosy could be due to drug resistance or growth of persisted organisms. Persists are drug sensitive organisms, which are either non-metabolizing or are lying dormant in the body so that they cannot be affected by the drugs during treatment. Once treatment is discontinued, they may multiply again and cause relapse $[19,26]$. As discussed many times for the duration of the WHO MDT leprosy is not like other disease in which negative laboratory result is needed to stop the treatment. There is also no laboratory test described to find out persisted bacilli in any specific tissue sample. Late relapse may probably occur due to re infection as these patients belong to high endemic region where there is high transmission rate. Re-infection is an extremely difficult condition to prove, especially in resource limited and endemic area but there are molecular methods like SNP and VNTR for strain typing or short range transmission $[27,28]$. Re infection may take a long time and may present after a few years as relapse, possibility is high especially in areas of high endemicity. In the present study, the mean relapse incubation period was found more as compared to other study findings [29]. However, there are proven genetic cause of relapse which occur due to defective macrophage function in them [30]. The reason for relapse in most cases in other studies was wrong categorization of MB cases as PB cases due to poor detection/ diagnostic techniques resulting in inadequate treatment $[1,31,32]$. 58 patients gave history of irregular MDT treatment before reporting to the hospital. Out of total, $35(29.9 \%)$ cases presented with a grade II deformity and 8 (6.8\%) were presented with grade I deformity among MB category which also shows poor IEC, and counseling of the patients along with poor follow up after RFT. Patch charting and proper maintenance of patient records (better electronic maintenance of health record) is needed to correctly diagnose relapse.

\section{Conclusion:}

Many of the countries in the world are at the verge of leprosy elimination; presence of relapse may be a big hurdle in the disease eradication process. Many factors have role in the relapse, so every relapse case should have a detailed clinical examination, proper history along with comparison with previous records and microbiological $/$ molecular investigation to find out the cause of the relapse. In case of drug resistance second line drugs should be in hand in case of drug resistance. For re infection cases transmission rate in the community should be cut down by vigorous case search by newer methods and treatment of subclinical cases.

\section{ACKNOWLEDGMENTS}

Declaration of Conflicting Interests: The authors declare that they have no conflict of interest.

Financial Disclosure: No financial support was received.

\section{REFERENCES}

1.Kaimal S, Thappa DM. Relapse in leprosy. Indian J Dermatol Venereol Leprol 2009; 75(2):126-35.

2.Poojabylaiah M, Marne RB, Varikkodan R, Bala N, Dandakeri S, Martis J. Relapses in multibacillary leprosy patients after Multidrug therapy. Leprosy Review 2008; 79 (3):320-324.

3. http://www.who.int/wer/2013/wer8835.pdf?ua=1

4.http://nlep.nic.in/pdf/Progress\%20report\%2031st\%2 0March\%202011-12.pdf

5.http://nlep.nic.in/pdf/ProgressReport2010-11.pdf

6.http://nlep.nic.in/pdf/Progress\%20report\%2031st\%2 0March\%202012-13.pdf

7.http://nlep.nic.in/pdf/Progress\%20report\%2031st\%2 0March\%202013-14.pdf

8.http://nlep.nic.in/pdf/Progress\%20report\%2031st\%2 0March\%202014-15\%20-.pdf

9.http://nlep.nic.in/pdf/revised\%20annual\%20report\% 2031st\%20March\%202015-16.pdf

10.http://www.searo.who.int/entity/global_leprosy_pro gramme/publications/8th_expert_comm_2012.pdf

11.Suzuki K, Udono T, Fujisawa M, Tanigawa K, Idani G, Ishii N. Infection during infancy and long incubation period of leprosy suggested in a case of a chimpanzee used for medical research. J Clin Microbiol 2010; 48(9):3432-3434.

12.Barker LP. Mycobacterium leprae interactions with the host cell: recent advances. Indian J Med Res 2006; 123:748-759.

13.Feldman M. The location dynamics of the US Biotech Industry: Knowledge externalities and the Anchor Hypothesis. J Industry Innovation 2003; 10 (3): 311-29.

14.Poojabylaiah M, Marne RB, Varikkodan R, Bala N, Dandakeri S, Martis J. Relapses in multibacillary 
leprosy patients after multidrug therapy. Lepr Rev 2008; 79(3):320-4.

15.Lwin K, Sundaresan T, Gyi MM, et al. BCG vaccination of children against leprosy: fourteen year findings of the trial in Burma. Bull World Heal Organ. 1985 ;63(6):1069-1078.

16. The SAGE Working Group on BCG Vaccines and WHO Secretariat. Report on BCG vaccine use for protection against mycobacterial infections including tuberculosis, leprosy, and other nontuberculous mycobacteria (NTM) infections. (available

at: http://www.who.int/immunization/sage/meetings/2 017/october/1_BCG_report_revised_version_onlin e.pdf.

17.Scheelbeek PFD, Balagon MVF, Orcullo FM, Maghanoy AA, Abellana J, Saunderson PR. A Retrospective Study of the Epidemiology of Leprosy in Cebu: An Eleven-Year Profile. PLoS Negl Trop Dis 2013; 19;7(9): e2444. doi: 10.1371/journal.pntd.0002444

18. Reddy S, Brown T, Drobniewski F. Detection of Mycobacterium tuberculosis from paraffinembedded tissues by INNO-LiPA Rif. TB assay: Retrospective analyses of Health Protection Agency National Mycobacterium Reference Laboratory data. J Med Microbiol 2010; 59(5):563566.

19.Maghanoy A, Mallari I, Balagon M, Saunderson P. Relapse study in smear positive multibacillary (MB) leprosy after 1 year WHO-multi-drug therapy (MDT) in Cebu, Philippines. Lepr Rev 2011; 82(1):65-69.

20.Waters MF, Rees RJ, Laing $A B$, et al. The rate of relapse in lepromatous leprosy following completion of twenty years of supervised sulphone therapy. Lepr Rev 1986; 57(0305-7518):101-109.

21.De Medeiros Brito MDF, Gallo MEN, Ximenes RAA. O retratamento por recidiva em hanseníase. An Bras Dermatol 2005; 80(3):255-260. (English Abstarct)

22. Pandey A, Uddin MJ, Patel R. Epidemiological shift in leprosy in a rural district of central India following introduction of multi-drug therapy (April 1986 to March 1992 and April 1992 to March 2002). Lepr Rev 2005; 76(2):112-118.

23.Oh S, Paik HY, Ju D. Dietary Habits, Food Intake and Functional Outcomes in Those with a History of Hansen's Disease in Korea'. Int J Lepr 1998; 66(I):34-42.

24.WHO. Guidelines for global surveillance of drug resistance in leprosy. World Heal Organ [Internet]. 2009;33. Available at: http://www.leprosyila.org/site/view/drug_resistance_guidelines2009_ 2.pdf
25.Li HY, Hu LF, Huang WB, et al. Risk of relapse in leprosy after fixed-duration multidrug therapy. Int $\mathrm{J}$ Lepr Other Mycobact Dis 1997; 65(2):238-245.

26.Gupta UD, Katoch K, Singh HB, Natrajan M, Katoch VM. Persister studies in leprosy patients after multi-drug treatment. Int $\mathrm{J}$ Lepr Other Mycobact Dis 2005; 73(2):100-104.

27. Turankar RP, Lavania M, Chaitanya VS, et al. Single nucleotide polymorphism-based molecular typing of $\mathrm{M}$. leprae from multicase families of leprosy patients and their surroundings to understand the transmission of leprosy. Clin Microbiol Infect 2014; 20(3):O142-0149.

28.da Silva Rocha A, Cunha M das G, Diniz LM, et al. Drug and multidrug resistance among Mycobacterium leprae isolates from Brazilian relapsed leprosy patients. J Clin Microbiol 2012; 50(6):1912-1917.

29.Shetty VP, Wakade AV, Ghate SD, Pai VV, Ganapati RR, Antia NH. Clinical, histopathological and bacteriological study of 52 referral MB cases relapsing after MDT. Lepr Rev 2005; 76(3):241252.

30.Sibley LD, Franzblau SG, Krahenbuhl JL. Intracellular fate of Mycobacterium leprae in normal and activated mouse macrophages. Infect Immun 1987; 55(3):680-685.

31.Kar HK, Sharma P. New lesions after MDT in PB and MB leprosy: a report of 28 cases. Indian J Lepr 80(3):247-255.

32.Abdul KS. An analysis of relapsed leprosy cases. Indian J Dermatol Venereol Leprol 2000; 66(3):126-128. 